\title{
The expressive force of primitive masculine sounds in Schwitters' sonata/poem Ursonate
}

\author{
Cynthia Whissell \\ Psychology Department, Laurentian University, Sudbury, Ontario, Canada, P3E 2C6
}

\section{Email address:}

cwhissell@laurentian.ca

\section{To cite this article:}

Cynthia Whissell. The Expressive Force of Primitive Masculine Sounds in Schwitters' Sonata/Poem Ursonate. International Journal of Language and Linguistics. Vol. 2, No. 6, 2014, pp. 343-347. doi: 10.11648/j.ij11.20140206.11

\begin{abstract}
This paper examines the ways in which language sounds with a masculine or feminine emotional character convey meaning and structure in Kurt Schwitters' expressive non-verbal poem the Ursonate. Schwitters emphasized the importance of sounds and the Merz (multi-modal) nature of art. The emotional character of sounds is associated with their physical qualities (e.g., frequency), their emotional associations, and the muscle movements involved in enunciating them: it was quantified, in this research, on the basis of emotional associations. Masculine consonants (e.g., r, t, p, g) predominate within the poem whose themes, segments, and movements are characterized by different combinations of masculine and feminine consonants and vowels. Performances of the Ursonate indicate the importance of expressive force in its rendition and masculine consonants allow for a forceful recitation.
\end{abstract}

Keywords: Expression, Masculinity, Non-Verbal Poetry, Sound

\section{Introduction}

In the first third of the $20^{\text {th }}$ century Kurt Schwitters developed, performed, and eventually published a poem composed of sound groupings rather than words ${ }^{1}$ (Schwitters, 2002, pp. 52-80). The poem had the structure of a sonata and was about 35 minutes long in performance. Although Schwitters' name is associated with those of the German Dada artists of the early $20^{\text {th }}$ century, he differentiated himself from this group (Schwitters, 2002, p. 217) and defined his approach as Merz, a term he invented ("My aim is the total Merz art work, which combines all genres into an artistic unity... to erase the boundaries between the arts," p. 218). Schwitters characterized his poem as a sonata in primitive or primal sounds (German: urlauten) and named it the Ursonate. He purposefully abandoned conventional modes of expression in favour of new ones ("The more intensively the work of art destroys rational objective logic, the greater the possibilities of the artistic form" p. 218) and he valued the expressive nature of poetry and its inter-media connection with music (Lichtenstein, 2008).

Schwitters directly addressed the masculinity of sounds in

\footnotetext{
1 The poem was published in 1932 in the $24^{\text {th }}$ and final issue of the art journal Merz (founded by Schwitters) and was downloaded from http://www.merzmail.net/ursonate.htm in August of 2013.
}

the Ursonate. He pointed to the "the strict military rhythm of the third theme which sounds totally masculine" and contrasted it to "the trembling, sheepishly tender fourth theme" (Schwitters, 2002, p. 236). In emphasizing the primitive and gendered nature of the sounds he employed, Schwitters was concluding that language sounds are meaningful. In a 1924 article on poetics, he noted that letters and the sounds associated with them in performance were the basic building blocks of poetry (2002, pp. 223-225). The sounds of the Ursonate are not formed into recognizable words so their meaning cannot come from a system of conventional signs; it has to come from the sounds themselves. The study of the unlearned or innate meanings of sounds, most often referred to as sound symbolism, has a long history. At roughly the same time as Schwitters was constructing his poem, Sapir (1929) and others (e.g., Hevner, 1937; Roblee \& Washburn, 1912) were publishing some of the earliest sound symbolism research in psychological journals. Sapir (1929) addressed size symbolism and Roblee \& Washburn (1912) examined the pleasantness of various sounds while Hervey (1937) assessed responses to poetry in terms of the "affective value" of word sounds (p. 420). Although early research was not specifically focused on the masculinity and femininity of sounds, gender associations can be understood as overlapping the factors studied (size, 
pleasantness, and affect).

Fónagy (1991) reviewed several studies that addressed the perceived masculinity-femininity of sounds as well as their size, softness, gentleness, hardness, etc. He noted, for example, that $r$ is perceived as a more masculine sound than 1 , which is more feminine (pp. 59, 61), and that $\mathrm{m}$ and 1 sound more feminine than $\mathrm{t}$ and $\mathrm{k}$ (p. 62). Explanations for the masculinity and femininity of sounds vary. Ohala's (1994) frequency code hypothesis refers to the difference in size between male and female organisms (and their vocal apparatus) and the resultant difference in fundamental frequency that encourages the perception of sounds that seemingly originate from smaller organisms (i.e., higher pitched sounds) as feminine. Fónagy (1991, pp. 50-55) points to effort or tension in the vocal apparatus as the source of meaning in sound (greater tension being associated with masculinity).

\section{Determining the Masculinity and Femininity of Sounds}

A different but not incompatible system for identifying the masculinity and femininity of sounds is offered by Whissell $(2000,2001)$ who noted that different sounds occur more frequently in men's or women's first names. Whissell (2001) also classified sounds into masculine and feminine categories in terms of their emotional meanings. Analyses of the sounds appearing in thousands of English words with known emotional associations had indicated that certain sounds tended to appear significantly more often in words of a particular emotional character. Within this model, sounds classified as masculine were more emotionally active and less pleasant while those classified as feminine were more pleasant and less active. This partitioning of the emotions may be in part stereotypical, but it also characterizes actual sex differences in personality (Whissell, 1996). Whissell (2000) suggested that facial expressions produced when sounds are enunciated overlap with those characteristic of the basic emotions, and that this overlap is partly responsible for the emotional meanings of sounds. For example, the enunciation of long e (as in "beet") produces a smile and conveys pleasant affect, while the enunciation of o (as in "alone") produces a droopy jaw and is associated with sadness.

Whissell's two systems of sound classification (appearance in first names, emotional associations) are in agreement in respect to most sounds, and their assignments generally conform to those in the research covered by Fónagy (1991). For example, plosive sounds such as $\mathrm{t}$ and $\mathrm{g}$ tend to occur more often in men's names, they are of an active/unpleasant character, and they are rated as masculine. In contrast, sounds such as 1 and m occur more frequently in women's names, they are of a pleasant/passive character, and they are rated as feminine. It was possible to classify most (94\%) of the sounds in the Ursonate as either masculine or feminine. The appearance of such sounds in different themes and movements structure the poem's meaning. The Ursonate has a short general introduction, three main movements, a cadenza, and a closing section. Subdivisions refer to classical parts of a sonata's structure such as the introduction, exposition, and resolution. The short second movement is a largo, and the third contains a scherzo and a trio. The poem is built around 18 themes and their variants.

\section{Method}

The data points for this research were the sounds in Schwitters' poem and their masculine or feminine nature. Schwitters employed 25 different letters in his poem and instructed that these should be pronounced in the German manner (Schwitters, 2002, p. 233). The poem was meant to be read phonetically (Perloff, 2010); its letters have a one-to-one association with sounds. Decisions as to the masculinity or femininity of each of letter-sound were made with the help of Jack Ox's invaluable phonetic transcription ${ }^{2}$, Axel Eichenberg's recitation ${ }^{3}$, a fragment of a recitation attributed to Schwitters himself ${ }^{4}$ and Schwitters' instructions to those wishing to perform the poem (Schwitters, 2002, pp. 233-237). Vowels whose pronunciation did not have an exact English equivalent were classified in terms of their closest English match in vowel space. Gender classification depended on the emotion associated with each sound (Whissell, 2000). The letter/sounds of the Ursonate were classified as feminine vowels (i, e, $\varepsilon$, œ), feminine consonants $(\mathrm{m}, \mathrm{v}, \mathrm{l}, \mathrm{n})$, masculine vowels (I, Y, a, u, o), and masculine consonants ( $\mathrm{p}, \mathrm{b}, \mathrm{t}, \mathrm{r}, \mathrm{f}, \mathrm{g})$. There are clear differences between masculine and feminine vowels in terms of their location in the vowel space depicted on the International Phonetic Association's website ${ }^{5}$ : feminine vowels are articulated further to the front and do not involve a fully open mouth while masculine ones are articulated further towards the back or involve a fully open mouth. Differences are also evident for consonants: masculine consonants are largely plosive while feminine ones include two nasals, a voiced fricative, and a lateral approximant. The gender classification of letter-sounds was conducted a priori (in advance of an examination of results) and not modified thereafter. The most common letter-sounds of the Ursonate were masculine consonants $(28 \%)$ followed by masculine vowels (24\%), feminine vowels $(23 \%)$, and feminine consonants (19\%). Unclassified sounds $(6 \%)$ fell into one of three categories: those with complex and overlapping emotional associations (e.g., d), those with no clear emotional associations (e.g., h) and those that had no workable English equivalent ( $\mathrm{z}$ which is pronounced as ts).

The gender category assigned to sounds did not depend on the gender or age of person reciting the poem. For male and female speakers of all ages, masculine sounds are more active-sounding and less pleasant-sounding than feminine

\footnotetext{
http://www.jackox.net/pages/Ursonate/handscore_Indx_.html

$3 \mathrm{http}: / /$ www.youtube.com/watch? $=\mathrm{C}-\mathrm{MUuNJifRM}$

${ }^{4} \mathrm{http}: / /$ www.youtube.com/watch? $\mathrm{v}=6$ X7E2i0 KMqM

${ }^{5} \mathrm{http}: / /$ www.langsci.ucl.ac.uk/ipa/fullchart.html
} 
sounds. The original word ratings on which sound assignments were calculated (as explained in Whissell, 2000) were provided by both men and women volunteers $15-55$ years of age. The steps employed in reaching final gender assignments for sounds in the Ursonate are summarized as follows: (1) words were rated in terms of their emotionality (Whissell, 2009); (2) statistical analyses were used to identify

sounds occurring with a high frequency in various type of words - e.g. passive and pleasant words; (3) emotional values were assigned to sounds (Whissell, 2000); (4) gender values were assigned on the basis of emotional values, as described above (Whissell, 2001).

\section{Results}

Table 1. The tone clusters of the poem, the proportion of sounds in them, and their relationship to Schwitters'themes.

\begin{tabular}{|c|c|c|c|c|c|}
\hline & \multicolumn{4}{|c|}{ Proportion of Sounds } & \multirow{3}{*}{$\begin{array}{l}\text { Associated } \\
\text { Themes }\end{array}$} \\
\hline & \multicolumn{2}{|c|}{ Vowels } & \multicolumn{2}{|c|}{ Consonants } & \\
\hline & Masc. & Fem. & Masc. & Fem. & \\
\hline 1: Masculine Consonants, Feminine Vowels & .13 & $.40^{1}$ & .27 & .10 & $1,3,5,16,18$ \\
\hline 2: Masculine and Feminine Consonants & .17 & .08 & .33 & .40 & $2,4,10,11$ \\
\hline 3: Masculine Consonants & .34 & .22 & .34 & .05 & $6,8,9,13,17$ \\
\hline 4: Masculine Vowels & .74 & .12 & .09 & .01 & $6,7,15$ \\
\hline 5: Feminine Consonants, Masculine Vowels & .48 & .00 & .08 & .42 & 12,14 \\
\hline
\end{tabular}

${ }^{1}$ Proportions appearing in bold print were those used to name the cluster. Clusters were named on the basis of their standing in relationship to other clusters for any type of sound. For example, Cluster 1 was named "Masculine Consonants" because it contained more such consonants than any other cluster. Although this cluster contained an equal proportion of masculine vowels, two other clusters $(4,5)$ contained more so it was not extreme in this respect.

Table 2. The Role of the Five Tone Clusters in the Structure of the Ursonate.

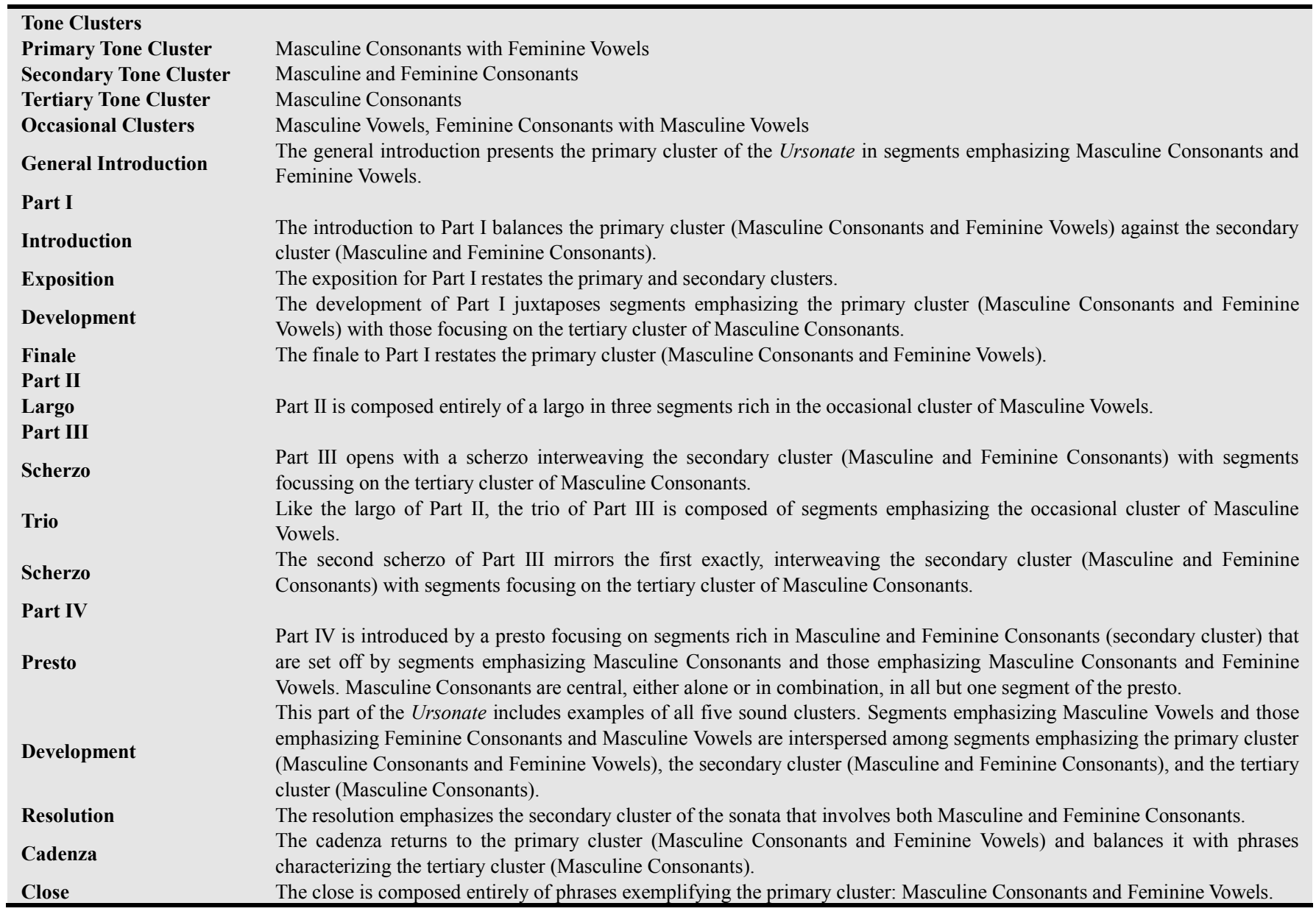

Preponderance of Masculine Sounds: There were more masculine $(52 \%)$ than feminine $(42 \%)$ sounds in the poem as a whole. The most common sounds were masculine consonants $(28 \%)$. Schwitters' emphasis on the masculinity of the third theme in comparison to the fourth (third theme:
Rinnzekete bee bee nnz krr müü?/ Ziiuu ennze ziiuu rinnzkirmüü; fourth theme: Rrummpff tillff too?) almost certainly rests on the presence of proportionally more masculine consonants in the former, and proportionally more feminine ones in the latter. 
Tone Clusters - Combinations of Sounds Characterizing Segments: Schwitters divided the Ursonate into 139 segments or musical phrases, with most segments exemplifying one of the 18 themes, a variation of a theme, or a combination of themes. Each segment was scored in terms of the proportional occurrence of each of the four types of sounds in it. In order to group similar segments together, a K-Means cluster analysis in SPSS with a Euclidian metric was employed to classify segments into coherent subgroups. The solution for five clusters of segments provided the most interpretable output and was associated with strong significant differences for all four of the measures employed in the clustering. Eta squared values were .80 for masculine vowels, .45 for masculine consonants, .67 for feminine vowels, and .83 for feminine consonants $(p<.001$ in all analyses). Clusters were named according to their extremity in respect to the use of a class of sounds in comparison to other clusters. The five clusters represented segments with Masculine Consonant and Feminine Vowels, those with Masculine and Feminine Consonants, those with Masculine Consonants, those with Feminine Consonants and Masculine Vowels, and those with Masculine Vowels (Table 1). Tone clusters were validated by a strong association with one or another of Schwitters' 18 themes (Table 1). Only one theme was characterized by more than one tone cluster (theme 6) and it tended to appear in combination with other themes.

The Structure of the Ursonate in Terms of Tone Clusters: The primary tone cluster of the Ursonate was the cluster of Masculine Consonants and Feminine Vowels (41 segments): it occurred in many segments and played a key role in the introduction to the poem and its denouement (Table 2). The secondary tone cluster was as frequent as the first but less centrally placed: it was characterized by the combination of Masculine and Feminine Consonants (41 segments). The central role of masculine consonants is affirmed by these tone clusters. The tertiary tone cluster included segments with a preponderance of Masculine Consonants (35 segments): again, the emphasis was on the role that masculine consonants play in structuring the poem. The remaining two clusters (Masculine Vowels, Feminine Consonants with Masculine Vowels, each with 11 segments) were rarer and were employed to colour the sonata, especially in the largo and cadenza. These are classified as occasional clusters. Table 2 describes how the tone clusters were employed in the structure of the poem. Clusters were arrived at statistically, but their meaningful distribution within the poem goes a long way towards providing construct validation for them. Entities derived from quantitative phonological analysis can be used to explicate the work.

\section{Discussion}

There is a limited amount of published research in the area of quantitative phonological analysis. An approach similar to the one described in this paper was applied to Milton's Paradise Lost (Whissell, 2011). Results revealed a clear three-part structure to the long poem. In the first part, the pleasantness of sounds rose as Christ defeated Satan in heaven. In the second part, pleasantness fell as Adam and Eve succumbed to temptation on earth. In the third and final part, pleasantness rose sharply as Christ's final victory was envisioned in the form of a promise to mankind. Where the language of a text is archaic (as in the case of Milton's poem) or non-verbal (as in the case of Schwitters'), phonological analysis can be used to discern the emotional structure of the work. In the case of the Ursonate, verbal descriptions provided by the author and comments made by those studying and performing the poem (see below) mesh seamlessly with quantitative results.

Schwitters' described the Ursonate as a "sonata in primal sounds" (Schwitters, 2002, p. 233) but the poem could just as easily be called a "sonata in masculine consonants." These are its most common sounds. Its main, secondary, and tertiary themes are represented by clusters including masculine consonants (Table 2). The poem opens and closes on themes represented by the cluster of Masculine Consonants and Feminine Vowels. In a sonata, the opening and closing segments are illustrative of both the key and the theme of the music. Within the Ursonate, masculine consonants characterize the exposition of the first part, the introduction to the fourth part (the presto), and its resolution (before the cadenza). Moreover, the different subparts of the poem can be clearly shown to be developed around clusters containing masculine consonants. It would be extremely difficult to recite a sonata composed entirely of masculine consonants. Within the Ursonate, feminine and masculine vowels act as a counterbalance to masculine consonants, but interestingly there are no clusters or themes pairing masculine vowels with masculine consonants or feminine vowels with feminine consonants. The validity of labeling the Ursonate as a "sonata in masculine consonants" does not depend on the absence of sounds other than masculine consonants within it but rather on the central role that such consonants play in its structure.

There are several recitations of the Ursonate available on Youtube $^{6}$. Besides the one by Schwitters himself there are notable recitations by the expert Jaap Blonk ${ }^{7}$. Schwitters' recitation is dramatically forceful, and this seems to have been typical of his performances (Rothenberg \& Joris, 2002, p. xvi). Blonk's performance accents the vigour of the poem by drenching the speaker in a red light. Blonk enunciates the poem's sounds in a larger-than-life manner and his facial expressions are forceful and tense. Of special interest is Blonk's enunciation of the phrase "ooooo..." which is a Masculine Vowel phrase that occurs early in the video. Blonk elongates his face outwards, producing what Ohala (1994) calls an "o-face." Ohala suggests that o-faces enable the emission of threatening vocalizations in many animals by lengthening the vocal tract and therefore lowering the

\footnotetext{
${ }^{6}$ http://www.youtube.com/watch?v=6X7E2i0KMqM http://www.youtube.com/watch?v=JgNL8-FdG-k

7 The complete Ursonate from 2007 recited by Blonk at http://vimeo.com/2687898
} 
fundamental frequency of the vocalization and making it more indicative of a larger and more threatening organism (i.e., a masculine one). The fact that masculine vowels are enunciated further back than feminine ones or with a fully open mouth also indicates that the working length of the vocal tract is longer in such vowels. As well, the tension in Blonk's face and his stance point to tension as a determinant of sound meaning, and especially of forcefulness or masculinity. In his introduction to a recitation of the complete poem, Jaap Blonk mentions that "the Ursonate is a sound poem made entirely of invented words without meaning"11. In saying this he is pointing to the fact that the "words" or collections of letters in the poem do not have a conventional meaning but rather an expressive one. He later points out that Schwitters was trying to "provoke and shock" his audience. Ox and van der Elst (2011) emphasize the importance of sense experiences in the development of knowledge and describe Ox's translation of the Ursonate from a sound to a pictorial representation.

Sounds are meaningful and the meaning of the Ursonate resides in its sounds, especially in its masculine consonants. "Masculinity" and "femininity" are labels: they encapsulate the difference between toughness and gentleness, primitivity and civilization, and even yang and yin. Most notably they emphasize the difference between the emotional focus of the tradition-busting artists of Schwitters' day and the complacency of the traditional art establishment (Hopkins, 2004, pp. 1-17).

\section{References}

[1] Fónagy, Ivan. (1991) La vive voix: essays de psycho-phonétique. Payot: Paris.

[2] Hevner, Kate. (1937) An experimental study of the affective value of sounds in poetry. American Journal of Psychology, 49, 419-434.

[3] Hopkins, David (2004) Dadaism and surrealism: a very short introduction. Oxford, UK: Oxford Univ. Press. Pp 1-17.

[4] Ohala, John. (1994) The frequency code underlies the sound-symbolic use of voice pitch. In Leanne Hinton, John J.
Ohala and Johanna Nichols, Eds. Sound symbolism. Cambridge, UK: Cambridge Univ. Press. Pp. 325-347.

[5] Ox, Jack. \& Van Der Elst, Judith. (2011) How metaphor functions as a vehicle of thought: creativity as a necessity for knowledge building and communication. Journal of Visual Art Practice, 20, 83-102.

[6] Lichtenstein, Sabine. (2008) Listening to Kurt Schwitters' Ursonate: a Dadaistic romantic transposition d'arts? Arcadia International Journal for Literary Studies, 38, 276-284.

[7] Perloff, Nancy. (2010) Schwitters' redesigned: a post-war Ursonate from the Getty Archives. Journal of Design History, 23, 195-203.

[8] Roblee, Louise. \& Washburn, Margaret F. (1912) The affective values of articulate sounds. American Journal of Psychology, $23,579-583$.

[9] Rotherberg, Jerome \& Joris, Pierre (2002). Introduction. In Schwitters, K. (2002) pppppp poems performance pieces proses plays poetics. Editors and Translators: Jerome Rothenberg \& Pierre Joris. Cambridge, MA: Exact Change.

[10] Sapir, Edward (1929) A study in phonetic symbolism. Journal of Experimental Psychology, 12, 225-239.

[11] Schwitters, Kurt. (2002) pppppp poems performance pieces proses plays poetics. Editors and Translators Jerome Rothenberg \& Pierre Joris. Cambridge, MA: Exact Change.

[12] Whissell, Cynthia. (2011) Sound and emotion in Milton's Paradise Lost. Perceptual and Motor Skills, 113, 257-267.

[13] Whissell, Cynthia. (2009) Using the revised Dictionary of Affect in Language to quantify the emotional undertones of samples of natural language. Psychological Reports, 105, 509-521.

[14] Whissell, Cynthia. (2001). Sound and emotion in given names. Names: A Journal of Onomastics, 49, 97-120.

[15] Whissell, Cynthia. (2000) Phonoemotional profiling: a description of the flavour of English texts on the basis of the phonemes employed in them. Perceptual Motor Skills, 91, 617-648.

[16] Whissell, Cynthia M. (1996). Predicting the size and direction of sex differences in measures of emotion and personality. Genetic Social and General Psychology Monographs, 122, 253-284. 